INRA Prod. Anim., 2010, 23 (5), 391-404

\title{
L'ingestion chez le poulet de chair : n'oublions pas les régulations à court terme
}

I. BOUVAREL ${ }^{1}$, S. TESSERAUD ${ }^{2}$, C. LETERRIER ${ }^{3,4,5,6}$

${ }^{1}$ ITAVI, Centre INRA de Tours, F-37380 Nouzilly, France

2 INRA, UR83 Recherches Avicoles, F-37380 Nouzilly, France

${ }^{3}$ INRA, UMR85 Physiologie de la Reproduction et des Comportements, F-37380 Nouzilly, France ${ }^{4}$ CNRS, UMR6175 Physiologie de la Reproduction et des Comportements, F-37380 Nouzilly, France

5 Université François Rabelais de Tours, F-37041 Tours, France

${ }^{6}$ Haras Nationaux, F-37380 Nouzilly, France

Courriel : bouvarel.itavi@tours.inra.fr

Quels mécanismes régulent l'ingestion ? A cette question, les nutritionnistes, les endocrinologistes, les éthologistes... n'apportent pas les mêmes réponses car ils considèrent souvent ce processus selon des pas de temps différents. Les programmes nutritionnels reposent sur des pas de temps d'une journée voire d'une semaine alors que les phénomènes associés à l'ingestion d'aliment ou au métabolisme de l'animal induisent des réponses à plus court terme.

Pour le nutritionniste, l'animal ingère des aliments afin de répondre à des besoins nutritionnels. Après ingestion, les composants de l'aliment sont rapidement dégradés au cours de la digestion. Les nutriments absorbés permettent alors d'assurer le métabolisme de base, la régulation de la température corporelle et les biosynthèses ainsi que les activités physiques. Mais l'animal consomme aussi en fonction de ses préférences et de la connaissance qu'il a de l'aliment. La consommation d'aliment est ainsi influencée par les besoins de l'individu mais aussi par ses préférences alimentaires.

La prise alimentaire est gouvernée par différents facteurs successifs : les facteurs sensoriels suivis de facteurs digestifs puis métaboliques, qui selon Blundell (1991) vont déterminer la satiété puis la faim (figure 1). La question est alors de savoir comment l'animal "harmonise» au fil du temps ses prises alimentaires avec ses besoins nutritionnels, pour atteindre un équilibre global.

\section{1 / Le rythme d'ingestion du poulet de chair}

De manière générale, un épisode de prise alimentaire comprend trois phases : une phase pré-ingestive caractérisée par la sensation de faim et la recherche active d'aliment, une phase prandiale correspondant à la période de prise alimentaire et au processus progressif de rassasiement, et une phase post-prandiale caractérisée par l'état de satiété dont la durée est variable

Figure 1. Cascade de satiété (adapté de Blundell 1991).

Facteurs métaboliques

\section{Facteurs digestifs}

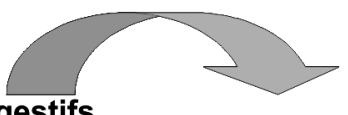

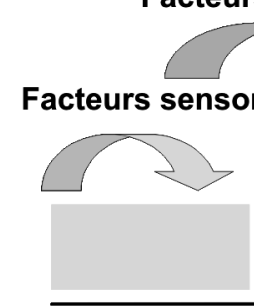

repas repas repas...

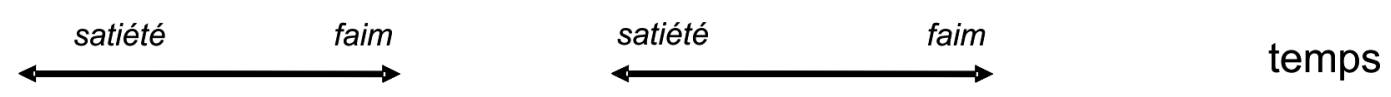


(Blundell 1991). La régulation des apports alimentaires peut se faire à la fois sur la quantité et la qualité des aliments ingérés au cours d'un épisode de prise alimentaire, ce qui met en jeu le processus de rassasiement, et sur la durée de l'intervalle entre deux prises alimentaires qui correspond à la période de satiété (Savory 1999).

Chez le poulet de chair, le comportement alimentaire peut varier énormément entre individus (nombre de prises alimentaires, durée et quantité d'aliment consommé par prise) avec pourtant des niveaux d'ingestion quotidiens identiques (Nielsen 2004). La définition du «repas» n'est donc pas aisée et dépend essentiellement du choix de la durée minimale de non consommation. Picard et al (1992) l'ont défini par une durée d'activité alimentaire ininterrompue de $5 \mathrm{~s}$ minimum et Bokkers et Koene (2003) et Howie et al (2009a et b), par une activité alimentaire qui peut être interrompue pendant respectivement $10 \mathrm{~s}$ et $150 \mathrm{~s}$ maximum. Les caractéristiques descriptives des repas sont donc différentes entre les auteurs. Pour Howie et al (2009a et b), plusieurs visites à la mangeoire ( 2 à 3 en moyenne selon les types génétiques) font l'objet d'un «repas». C'est pourquoi nous parlerons par la suite plutôt «d'accès alimentaires» que de repas. Les prises alimentaires ont généralement une durée moyenne très courte, de l'ordre de quelques minutes, et sont entrecoupées de périodes plus longues, variant de 15 à 30 minutes selon l'âge des animaux (tableau 1). Le nombre d'accès à la mangeoire chez des poulets en fin d'élevage est de l'ordre de 30 (Howie et al 2009a et b) à 50 fois par jour (Weeks et al 2000).

Le rythme d'ingestion des volailles est dépendant également de la forme de l'aliment (farine vs granulé par exemple) et des conditions d'élevage. Le programme lumineux conditionne l'activité des animaux avec un pic d'activité en début et en fin de période éclairée (Buyse et al 1993, Richard et al 1997), les volailles mangeant très peu durant la phase d'obscurité comme c'est le cas chez les oiseaux diurnes en conditions naturelles. La facilitation sociale, c'est à dire l'initiation ou l'augmentation de la fréquence de comportements en réponse à des congénères engagés dans les mêmes comportements (Clayton 1978), peut aussi modifier les rythmes d'ingestion, avec des patterns d'excitation synchronisée d'ingestion de groupe (Collins et Sumpter 2007). Le rythme des accès à l'aliment est alors dépendant d'une adaptation de l'animal à son environnement (Picard et al 1997).

Ainsi, les accès alimentaires chez les volailles présentent une fréquence importante et variable qui se comptabilise à l'échelle de minutes. Les unités d'alimentation sont conçues et appliquées sur la base de pas de temps d'une journée, alors que bien des processus nutritionnels déterminant des réponses aux régimes se produisent selon des pas de temps plus courts (Sauvant et al 1995). Il paraît donc important de prendre en compte les évènements alimentaires à différentes échelles de temps : de la journée et au-delà mais aussi de l'heure et de la minute, pour comprendre comment évolue la prise alimentaire au cours du temps.

\section{2 / Des signaux neuroendo- criniens et métaboliques intervenant à long terme}

L'ingestion est régulée à long terme (journée et au-delà) au niveau central depuis des boucles de rétroaction des tissus périphériques, afin d'assurer l'équilibre énergétique, et ceci de concert avec la recherche de l'homéostasie protéique et de l'homéothermie.

Tableau 1. Durée moyenne $( \pm E T)$ des prises alimentaires (1activité ininterrompue d'au minimum $5 \mathrm{~s}$; 2activité qui peut être interrompue pendant $10 \mathrm{~s}$ maximum ou ${ }^{3}$ et 4150 s) et intervalle entre les prises chez le poulet de chair.

\begin{tabular}{|l|c|c|c|}
\hline \multicolumn{1}{|c|}{ Référence } & $\begin{array}{c}\text { Age } \\
\text { (semaine) }\end{array}$ & $\begin{array}{c}\text { Durée } \\
\text { (minute) }\end{array}$ & $\begin{array}{c}\text { Intervalle } \\
\text { (minute) }\end{array}$ \\
\hline 1 Picard et al 1992 & 3 & $2,4 \pm 0,4$ & 15 \\
\hline 2 Bokkers et Koene 2003 & 4 & 2,8 & 10 \\
\hline 3 Howie et al 2009a & 7 & 3,6 & 26 \\
\hline & & $8,1 \pm 0,1$ & \\
4 à 5 & (A) $7,38 \pm 0,05$ & $2,17 \pm 0,02$ \\
& 2 à 5 & (B) $7,20 \pm 0,05$ & $1,31 \pm 0,02$ \\
& & (C) $5,68 \pm 0,03$ & $1,95 \pm 0,01$ \\
& & (D) $6,18 \pm 0,05$ & $2,37 \pm 0,02$ \\
\hline
\end{tabular}

* les données ont été collectées pour 4 lignées différant par leur vitesse de croissance : de $2,4 \mathrm{~kg}(\mathrm{~A})$ à $1,6 \mathrm{~kg}(\mathrm{D})$ à 35 jours d'âge.

Le contrôle de l'équilibre énergétique est considéré par les nutritionnistes comme le principal facteur de régulation du comportement alimentaire. La régulation coordonnée de l'ingestion et des dépenses énergétiques doit répondre à des signaux environnementaux externes (disponibilité de l'aliment, composition de l'aliment, photopériode, température, facteurs de stress) et à des signaux physiologiques internes (stockage d'énergie, hormones et niveaux en nutriments et métabolites). Le cerveau joue un rôle pivot dans les processus d'intégration de tous ces signaux. L'adaptation de l'ingestion intervient à long terme, c'est à dire sur plusieurs jours voire plusieurs semaines chez l'Homme par exemple (Mc Minn et al 2000).

\section{1 / Au niveau central}

\section{a) Contrôle de l'équilibre énergétique}

La région hypothalamique représente le point de convergence de nombreuses informations périphériques et participe au contrôle de l'équilibre énergétique corporel de la prise alimentaire. Elle contient de multiples voies nerveuses peptidergiques divisées en deux catégories élémentaires : anaboliques et cataboliques, impliquées dans la régulation de l'ingestion et l'homéostasie énergétique (Woods et al 1998). La voie anabolique entraîne une augmentation nette de l'énergie ingérée et du stockage, tandis que la voie catabolique résulte en une baisse nette de l'énergie ingérée et du stockage.

Chez le poulet, le système mélanocortine central, constitué d'une collection de neurones exprimant les neuropeptides Y (NPY) et Agouti-related peptide (AgRP), et d'une seconde collection exprimant la proopiomélanocortine (POMC), fait partie des réseaux nerveux impliqués dans la régulation conjointe de l'ingestion et de la dépense énergétique, actuellement les mieux caractérisés (Richards et ProszkowiecWeglarz 2007) (figure 2). La stimulation des neurones exprimant NPY/ AgRP (anabolique) provoque une augmentation nette de l'ingéré énergétique et du stockage, tandis que la stimulation des neurones exprimant POMC (catabolique) entraîne une baisse de l'énergie ingérée et du stockage.

\section{b) Contrôle de l'homéothermie}

La régulation centrale de l'ingestion et de la balance énergétique implique l'intégration des signaux environnementaux, comme la disponibilité de l'aliment, la photopériode mais aussi la température, qui revêt une importance capitale chez le poulet de chair à croissance rapide. 
Figure 2. Modèle de régulation à long terme (en gris, représentée par la leptine et l'insuline) et à court terme (en noir, représentée par la cholécystokinine) de l'ingestion chez la volaille (adapté de Richards et Proszkowiec-Weglarz 2007).

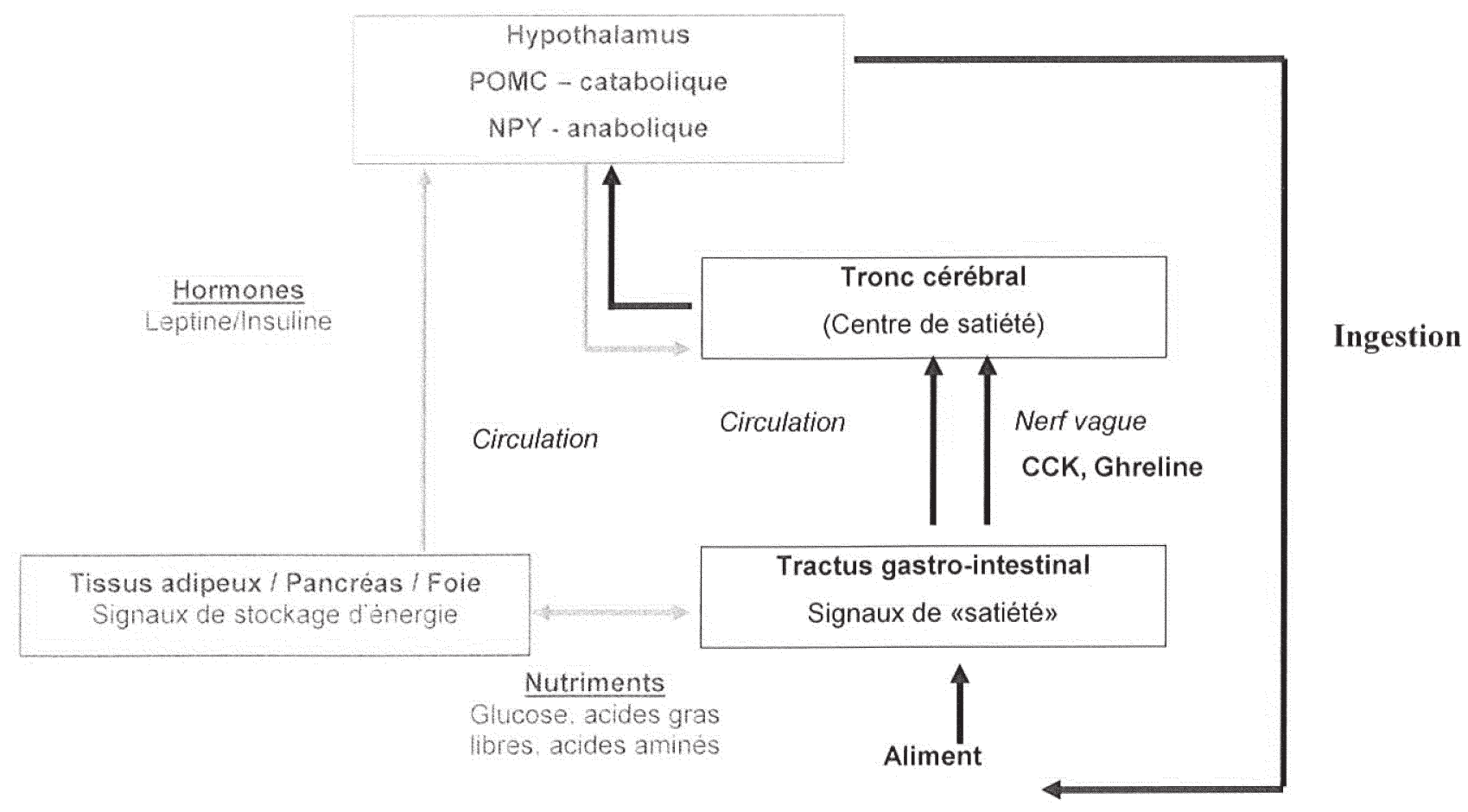

CCK = cholécystokinine $; \mathrm{NPY}=$ Neuropeptide $\mathrm{Y} ; \mathrm{POMC}=$ ProOpioMélanoCortine.

La production de chaleur ou thermogenèse est une des composantes importantes de la dépense énergétique utilisée par l'animal pour maintenir sa température corporelle. La température est régulée au niveau de l'hypothalamus, qui réagit en activant la thermogenèse ou la thermolyse. De nombreuses hormones interviennent dans la régulation des processus thermogéniques: de manière directe par exemple avec les hormones thyroïdiennes (Collin et al 2009) et le glucagon (Duchamp et al 1992), ou indirecte avec l'insuline (Geraert 1991) voire la leptine (Dridi et al 2008). La température corporelle des poulets n'est jamais constante, mais ne peut supporter des variations excédant 2 à $3^{\circ} \mathrm{C}$ sans mettre en péril la survie de l'animal (De Basilio et Picard 2002). La capacité des oiseaux à éliminer la chaleur par voie sensible (rayonnement, conduction, convection) ou par évaporation est limitée. Sous de fortes chaleurs, les volailles réduisent leur ingestion en fonction de l'élévation de la température pour limiter la production de chaleur, de manière à maintenir leur homéothermie. La sélection génétique sur la vitesse de croissance a entraîné une augmentation importante des taux métaboliques. Néanmoins, ceci n'a pas été accompagné par un développement comparable des viscères, entraînant une plus faible thermotolérance (Yahav 2009). Un problème majeur pour ces animaux est de dissiper la chaleur produite par l'ingestion d'aliment et le métabolisme (Yalçin et al 1997a et b). L'acclimatation à la chaleur très précoce, par adaptation épigénétique, c'est-à-dire durant des phases critiques du développement au moment de l'embryogenèse, apparaît comme une voie d'adaptation intéressante (Yahav 2009).

Les régulations visant l'équilibre énergétique et l'homéostasie thermique interfèrent donc et influencent conjointement l'ingestion. Ainsi, théoriquement, pour des conditions de température optimale, le niveau d'ingestion dépend de la teneur énergétique de l'aliment, l'équilibre de la balance énergétique se concrétisant par l'ajustement de l'énergie ingérée à la concentration de l'aliment. En conditions thermiques limitantes, un ajustement a lieu pour assurer l'homéothermie. Ces ajustements en fonction de la concentration énergétique de l'aliment et de la température ambiante sont bien observés chez le poulet à croissance lente, non sélectionné sur sa vitesse de croissance (Quentin et al 2003). Chez le poulet à croissance rapide, ce n'est que quand les conditions deviennent limitantes sur le plan thermique qu'un ajustement de la consommation a lieu assez rapidement (dans la journée) en fonction de la concentration énergétique de l'aliment. Ses faibles capacités de thermolyse constituent ainsi un facteur de régulation majeur de l'ingestion. En conditions thermiques non limitantes, le poulet de chair à croissance rapide consomme plus d'énergie avec un aliment à haute concentration énergétique qu'avec un aliment moins concentré (Quentin et al 2003). Ceci explique probablement le fait que la corrélation négative observée entre la quantité ingérée et la concentration énergétique de l'aliment n'est pas très forte chez le poulet à croissance rapide (Svihus 2007).

\section{2 / Contrôle du stockage d'énergie au niveau du cerveau}

L'excès d'énergie ingérée est stocké sous forme de glycogène et surtout de triglycérides, pouvant ensuite être utilisés comme source d'énergie. Pour assurer un équilibre, la communication du niveau de stockage d'énergie du tissu périphérique vers le système nerveux central est réalisée par des connexions entre les sites de stockage d'énergie (le foie et les tissus adipeux) et le cerveau. Plusieurs dizaines de molécules sont connues pour moduler l'ingestion chez la volaille.

L'une d'elles, la leptine, une adipocytokine produite et sécrétée dans la circulation sanguine par les cellules adipeuses, illustre bien cette forme de signal, ainsi que vraisemblablement l'insuline (figure 2).

Chez les mammifères, des changements dans le niveau circulant de leptine sont perçus au niveau de l'hypothalamus 
qui régule les changements à long terme de la balance énergétique, en activant ou inhibant des voies spécifiques anaou cataboliques. La leptine inhibe la prise alimentaire et augmente la dépense énergétique par l'intermédiaire de son interaction avec ses récepteurs spécifiques dans l'hypothalamus. Elle active les voies anorexigéniques (POMC) et inhibe les voies orexigéniques (NPY) (figure 2). Chez le rat, la leptine a un effet sur la taille des repas (réduction), qui n'est pas compensé par une augmentation de la fréquence des repas (Flynn et al 1998).

Chez les espèces aviaires, le rôle de la leptine et de son récepteur dans la régulation du poids et des dépenses énergétiques, est moins bien connu. Le gène de la leptine a été cloné et séquencé chez le poulet par Taouis et al (1998) et Ashwell et al (1999), mais une controverse quant à son existence demeure toutefois (Sharp et al 2008). Le gène du récepteur de la leptine a été néanmoins identifié et caractérisé chez le poulet et la dinde, et apparaît tout à fait similaire à celui des mammifères (Richards 2003). De plus, l'administration de leptine exogène est active et réduit la prise alimentaire chez les espèces aviaires (Dridi et al 2000, 2005, Denbow et al 2000, Taouis et al 2001, Cassy et al 2004, Bogatyrev et al 2010). Seule, une publication n'indique pas de baisse d'ingestion (Bungo et al 1999). Il apparaît donc que, comme chez les mammifères, la leptine ou une hormone apparentée pourrait exercer un effet anorexigène signalant le statut énergétique chez les oiseaux (Richards et Proszkowiec-Weglarz 2007).

Chez le poulet comme chez les mammifères, la concentration en «leptine immunoréactive» diminue lors du jeûne et s'élève après le repas, certainement en relation avec la sécrétion d'insuline qui est capable de stimuler l'expression du gène de la leptine par le foie (Cassy et al 2001). L'effet maximal de l'hormone sur l'ingestion est atteint après 4 heures de réalimentation (Dridi et al 2000). Le poulet à croissance rapide est moins réceptif aux concentrations de «leptine» périphériques que le poulet à croissance lente (sélectionné pour la ponte), suggérant que la plus grande vitesse de croissance du poulet doit être liée à une moindre sensibilité des facteurs anorexigéniques (Cassy et al 2004). Chez ce type de poulet, la «leptine» agit en effet sélectivement sur les voies anaboliques (NPY) plutôt que sur les voies cataboliques (POMC) (Dridi et al 2005). La densité des récepteurs du NPY est d'ailleurs deux à trois fois plus élevée chez le poulet à croissance rapide que chez la souche Leghorn (ponte) (Merckaert et Vandesande 1996).
Un lien entre les réserves énergétiques et la modulation des activités métaboliques a été fait récemment avec l'identification d'une enzyme intervenant dans le maintien de l'homéostasie énergétique cellulaire : l'adénosine monophosphate-activated protein kinase (AMPK). L'AMPK est un régulateur clé du métabolisme énergétique, jouant à la fois sur les métabolismes glucidique et lipidique. Ce senseur énergétique est sensible aux variations du rapport AMP/ATP. Les effets d'une activation de l'AMPK sur le métabolisme énergétique s'observent chez le poulet au niveau hépatique et d'autres tissus périphériques (muscles, tissu adipeux et pancréas) et au niveau hypothalamique (Richards et Proszkowiec-Weglarz 2007).

\section{3 / Influence des nutriments}

L'animal cherchant à assurer son équilibre énergétique, adapte son ingestion en fonction des nutriments disponibles. L'énergie apportée par les aliments est disponible sous la forme principale de glucides et de lipides, mais également de protéines. Chez les oiseaux, le site majeur de la lipogenèse est le foie. Lorsque la balance énergétique est positive, l'expression des gènes lipogéniques est augmentée, conduisant à une augmentation de la production de triglycérides et du stockage de tissu adipeux (Richards 2003). En retour, le niveau d'expression du gène de la leptine ou hormone apparentée affecte l'ingestion d'aliment, de manière à avoir un ajustement approprié de la balance énergétique (Richards 2003, figure 2).

Chez le rat et chez l'Homme, on considère que les protéines ont le pouvoir de satiété le plus élevé, et les lipides le plus faible, les glucides étant intermédiaires (Stubbs et al 1997). Chez les mammifères, la thermogenèse induite par l'ingestion d'aliment est plus élevée pour un régime à haute teneur en protéines comparé à des régimes à haute teneur en glucides ou lipides. Toutefois chez le poulet, avec un modèle de mise à jeun suivie d'une réalimentation, il n'a pas été montré de différences majeures en terme de thermogenèse induite par l'aliment avec une substitution des lipides par des protéines (Swennen et al 2007). Il a été également montré que l'augmentation de la teneur en protéines en substitution de l'amidon ne modifie pas la production de chaleur ainsi que ses composantes, dont la production de chaleur induite par l'aliment (Noblet et al 2007).

Concernant le cas particulier des aliments riches ou pauvres en protéines, l'anorexie induite par l'ingestion d'un aliment riche en protéines (apport en acides aminés essentiels (AAE) largement supérieurs au besoin : $\times 2,5)$ est liée chez le rat à l'effet satiétogène des protéines et également à une moindre palatabilité (Bensaïd et al 2003). Dans le cas de régimes à faible teneur en protéines (non couverture des besoins en $\mathrm{AAE}$ : $-50 \%$ ), le jeune rat répond par une augmentation de son ingestion (White et al 2000). Chez la volaille, des modifications de l'ingestion sont observées également en fonction des teneurs en protéines de l'aliment lorsque l'apport en énergie est maintenu constant. Toutefois, les variations de teneur en protéines testées sont beaucoup plus faibles que dans les expériences décrites précédemment réalisées chez le rat. Une teneur réduite en protéines de l'aliment de $20 \%$ conduit à un maintien de l'ingestion ou à une légère hyperphagie (Pesti et Fletcher 1984, Rosebrough et Steele 1985, Fancher et Jensen 1989, Bregendahl et al 2002, Noy et Sklan 2002, Smith et Pesti 2002), tandis que l'ingestion est réduite avec une teneur élevée en protéines $(+20$ à $+30 \%)$ (Rosebrough et Steele 1985, Noy et Sklan 2002).

\section{3 / Des signaux intervenant à court terme}

La régulation de l'ingestion à court terme (moins d'une heure) est liée à la nécessité de limiter l'encombrement de l'aliment ingéré et d'assurer des apports énergétiques et en nutriments réguliers. Chez les volailles, elle est vraisemblablement effective selon un pas de temps inférieur à une heure eu égard à la rythmicité de la prise alimentaire. Elle fait intervenir des signaux provenant $\mathrm{du}$ tractus gastro-intestinal et agissant au niveau central, les signaux de satiété ayant un effet sur la taille de la prise alimentaire.

\section{1 / Signaux mécaniques}

L'initiation des repas ainsi que leur arrêt sont associés au taux de remplissage du tractus digestif, qui dépend à la fois de la distension de l'appareil digestif et de la vitesse de passage des digesta. Dans le cas des poulets à croissance rapide, ces effets mécaniques revêtent une importance capitale dans la régulation de l'ingestion, les poulets consommant jusqu'aux limites de leur capacité physique (Bokkers et Koene 2003).

Le jabot, dilatation de l'œsophage, constitue un réservoir régulateur du transit digestif, les particules ingérées y subissant une hydratation. La réplétion du jabot réduit la prise alimentaire mais seulement au-delà d'un seuil (Savory 1979, 1985). Le niveau d'encombre- 
ment de l'aliment, mesuré par sa densité volumique, peut expliquer des variations d'ingestion. Par exemple, la plus faible consommation d'un aliment contenant de l'isolat de soja comparé à du tourteau de soja paraît s'expliquer par sa plus faible densité volumique (Shelton et al 2005).

Le gésier, troisième poche digestive des oiseaux, possède comme le jabot des récepteurs sensibles à la distension (Denbow 1994), qui modulent et coordonnent les différentes phases de contraction en fonction des caractéristiques du chyme. Les grosses particules y séjournent de l'ordre de $30 \mathrm{~min}$ à $4 \mathrm{~h}$ selon leur résistance, leur forme et leur plasticité, tandis que la fraction liquide y séjourne très brièvement, environ $15 \mathrm{~min}$, la vidange du gésier ne laissant passer que les particules dont la taille ne dépasserait pas 0,5 à $1,5 \mathrm{~mm}$ (Sklan et al 1975, Ferrando et al 1987, Shires et al 1987, Carré 2000). Le développement du gésier, et donc sa capacité de broyage et de contrôle du transit intestinal, dépend de la taille des particules présentes. Nir et al (1994b) ont mesuré chez des poulets, un niveau d'ingestion plus élevé entre 7 et 21 jours et un gésier plus gros, lorsqu'un aliment est distribué sous forme de farine de particules de taille moyenne plutôt que fine. L'aliment granulé induit aussi des effets mais ces derniers sont plus limités qu'avec la farine, certainement du fait de la diminution de la taille des particules du mélange lors du process mis en jeu pour la granulation (Svihus et al 2004). Lors de l'ingestion de granulés, les bâtonnets sont désagrégés dans le jabot. Le gésier joue plutôt un rôle d'organe de transit que de broyage et de mélange de l'aliment avec les enzymes digestives (Amerah et al 2007) et la vitesse de passage de l'aliment est alors augmentée.

Au niveau intestinal, le temps de rétention dans le duodénum est court, de l'ordre de 3 à $7 \mathrm{~min}$, de même que celui dans la partie supérieure du jéjunum, de l'ordre de 4 à 5 min (Sklan et al 1975, Shires et al 1987). La mise sous tension du proventricule-gésier, du duodénum et du premier tiers de l'iléon par l'aliment inhibe le péristaltisme œsophagien et induit alors la fin du repas (Chaplin et al 1992).

\section{2 / Signaux de satiété}

Les signaux physiques ne sont toutefois pas les seuls à contribuer au rassasiement. La présence d'aliment dans le tractus gastro-intestinal stimule la sécrétion d'un grand nombre de peptides (plus d'une vingtaine sont répertoriés), contrôlant la motilité intestinale et les sécrétions digestives, tout en servant de signaux de satiété dans le cerveau
(Jensen 2001). Ce système de régulation de l'ingestion, également appelé «système de satiété périphérique» agit à court terme, car les effets des peptides ont une courte durée de vie. Parce que les signaux sont seulement actifs durant de courtes périodes, ils sont effectifs chez les mammifères dans la régulation de la taille des repas mais ne sont pas capables de produire des changements à long terme aux niveaux de la balance énergétique et du poids corporel, une augmentation de la fréquence des repas pouvant être observée (Mc Minn et al 2000).

Chez le poulet, ces signaux sont transmis vers le tronc cérébral par l'activation de voies afférentes vagales ou via des sécrétions de substances «signal» dans le circuit sanguin (Richards et Proszkowiec-Weglarz 2007) (figure 2).

Deux types de signaux produits par le tractus gastro-intestinal sont impliqués : ceux qui stimulent la consommation alimentaire et ceux qui l'inhibent. Pour exemple, la cholécystokinine (CCK). inhibitrice potentielle de l'ingestion, a été bien étudiée chez les oiseaux, comme la bombésine et la gastrine (Denbow 1994, Kuenzel 1994, Jensen 2001). La CCK stimule la vidange gastrique et la sécrétion d'enzymes pancréatiques pour aider à la digestion, ce qui favorise la fin du repas et la satiété postprandiale, mais elle agit aussi sur les fibres du nerf vague, qui innervent l'intestin, le foie et le pancréas et sont connectés au centre de satiété du tronc cérébral (Richards 2003). De nombreuses questions restent en suspens notamment quant à la nature des mécanismes cellulaires en amont des évènements que sont la libération de la CCK par les cellules intestinales et son action sur les terminaisons vagales.

Au contraire de la CCK, la ghréline stimule l'ingestion chez les mammifères, en jouant un rôle dans l'initiation des repas (Wren et al 2000). La ghréline est produite par le proventricule du poulet mais curieusement, elle inhibe l'ingestion de poulets quand elle est administrée dans les ventricules cérébraux (Furuse et al 2001, Saito et al $2002,2005)$ et par voie périphérique (Geelissen et al 2006). Ceci semble indiquer une différence liée à l'espèce, dans le fonctionnement des peptides provenant de l'intestin (Kaya et al 2007). Le régime alimentaire affecte l'expression de la ghréline chez les oiseaux, tout comme chez les rongeurs ou l'Homme. Chez le poulet, le passage à un aliment moins riche en protéines (20 à 18\%), et plus énergétique, conduit à une diminution du niveau de l'expression des ARNm de la ghréline dans le proventricule (Chen et al 2007).

\section{4 / Les signaux sensoriels et l'expérience conditionnent les réactions immédiates vis-à-vis de l'aliment}

Le poulet domestique a besoin d'explorer et de connaître son environnement rapidement après l'éclosion. Il doit être notamment capable de discriminer ce qui est comestible ou toxique pour lui sans l'aide de sa mère. Les capacités sensorielles du poulet et les mécanismes de mémorisation des expériences alimentaires déterminent le comportement de l'animal face à un nouvel aliment. Il convient ainsi de dissocier, dans l'analyse comportementale, ce qui relève de réactions sensorielles immédiates spontanées, de ce qui provient d'apprentissages, et donc d'informations stockées à long terme.

\section{1 / Les réactions sensorielles chez les oiseaux}

Les signaux sensoriels conditionnent la réponse à très court terme ( $<$ minute). Parmi eux, les capacités visuelles et tactiles sont particulièrement utilisées par les volailles pour apprécier leur aliment. Le comportement alimentaire dépend de ces différentes perceptions qui interagissent entre elles et dépendent aussi de l'expérience de l'animal.

\section{a) La vision}

La vision est la première concernée pour la détection de l'aliment dans l'environnement et elle revêt une grande importance pour les oiseaux. La perception visuelle des particules alimentaires implique des tâches complexes et précises réalisées rapidement (Picard et al 2002). Les oiseaux sont capables de percevoir avec une grande acuité les détails des aliments du fait d'une densité importante de cellules cônes et bâtonnets dans la rétine (Moran 1982). La vision latérale relativement indépendante entre chaque œil permet au poulet une perception précise de détails rapprochés dans deux secteurs situés à une distance angulaire de $34-39^{\circ}$ et $61-66^{\circ}$ du bec. Le poulet est capable de réaliser deux tâches simultanément : rechercher de l'aliment et guetter d'éventuels prédateurs grâce respectivement, aux hémisphères gauche et droit du cerveau (Rogers 1995). L'exposition à la lumière de l'embryon durant les trois derniers jours d'incubation conduit au développement de la latéralisation des capacités à picorer des grains et à détecter des prédateurs (Rogers et al 2004, Dharmaretnam et Rogers 2005).

Les volailles sont attirés par des particules brillantes (Rogers 1995) et les 
particules les plus claires (Chagneau et al 2006, Lecuelle et al 2010b). Weeks et al (1997) indiquent, pour le poulet de chair, une consommation plus importante d'aliments colorés en jaune et en rouge comparés au vert et au bleu. La perception des couleurs et l'effet de celles-ci sur le comportement des volailles dépendent de leur sensibilité spectrale qui est légèrement différente de celle de l'Homme (380 à $700 \mathrm{~nm})$. Ce dernier possède trois types de cônes qui lui permettent de percevoir les trois couleurs primaires, le rouge, le vert et le bleu, et a donc une vision trichromatique, tandis que les oiseaux ont une vision tétrachromatique (Burkhardt 1982, Osorio et al 1999). Ils possèdent en effet un quatrième type de cône, qui est sensible à la lumière ultraviolette, et peuvent donc percevoir quatre couleurs primaires, la couleur supplémentaire étant celle des ultraviolets (UV). Emmerton (1983) a démontré que les pigeons sont capables d'excellentes discriminations de motifs dans les UV. Les pigeons et plusieurs autres espèces aviaires utilisent leur sensibilité aux UV pour voir des objets tels que le plumage ou des fruits qui reflètent la lumière UV (Burkhardt 1982).

Ainsi, la vision des oiseaux est un élément important à prendre en considération comme facteur de variation de la consommation à court terme. De nouveaux outils en cours de développement devraient permettre de mieux caractériser les aliments et faciliter la prise alimentaire.

\section{b) L'olfaction}

Le système olfactif des oiseaux est proche de celui des amphibiens, reptiles et mammifères. Le degré de développement de l'épithélium olfactif varie substantiellement entre oiseaux : la taille et la complexité du système olfactif sont plus importantes par exemple chez les espèces carnivores ou piscivores que chez les espèces frugivores ou granivores. Le poulet se situe au milieu d'un classement basé sur la taille relative du bulbe olfactif de 124 espèces aviaires (Jones et Roper 1997). Le ratio entre le diamètre du bulbe olfactif et celui de l'hémisphère ipsilatéral est de $15 \%$ chez le poulet, le minimum étant de $3 \%$ chez la mésange à tête noire, et le maximum de $37 \%$ chez le pétrel des neiges. De nombreuses molécules sont perçues et modifient le comportement des volailles (Jones et Roper 1997). Des réactions plus ou moins importantes sont observées selon l'origine de l'odeur : le poussin réagit plus à une odeur de menthe qu'à celle d'orange et de lavande (Porter et al 1999). Le poulet montre une préférence pour les triglycérides à longue chaîne comparé aux triglycérides à chaîne moyenne, plus facilement oxydables, tandis que sans bulbe olfactif, il n'exprime pas de préférence (Mabayo et al 1996). Le poussin d'un jour montre des réponses graduelles à une augmentation de la concentration d'odorants comme l'eugenol, l'isoamyl-acétate et l'allyl sulfide. La concentration croissante de l'odeur est d'abord non détectée, induit ensuite des réponses positives, puis des réactions négatives de plus en plus fréquentes (Burne et Rogers 1996).

Ainsi, l'olfaction pourrait jouer un rôle dans le processus de reconnaissance de l'aliment, mais qui paraît toutefois moins important que celui joué par la vision (Jones et Roper 1997). En effet, les réactions à une variation de l'odeur de l'aliment, qui sont détectables à court terme, disparaissent rapidement si l'animal ne subit pas d'effet négatif ou positif associé (Picard et al 2000).

\section{c) Le toucher}

La perception tactile des particules alimentaires est essentiellement faite par le bec, qui dispose d'un équipement sensoriel hautement spécialisé constitué de mécanorécepteurs (corpuscules de Merkel et Herbst) regroupés dans les 15-20 papilles dermiques situées juste sous la couche cornée du bec (Gentle et Breward 1986). La durée d'un coup de bec est relativement brève (130 à 170 $\mathrm{ms}$ ) et deux coups de bec successifs sont séparés d'une phase d'observation, deux à trois fois plus longue. La majorité des coups de bec ne vise pas à prendre, mais à toucher une particule alimentaire et a donc un objectif purement exploratoire (Picard et al 2000). Un tiers des coups de bec seulement aboutit à l'ingestion de nourriture (Yo et al 1997). La taille, la forme et les propriétés de surface des particules interviennent ainsi dans la prise alimentaire.

Les volailles consomment les particules suffisamment grosses pour être saisies efficacement par le bec (Rogers 1995). Ces préférences correspondent à une optimisation énergétique (bénéfice/ coût) du comportement alimentaire (Collier et Johnson 2004). Les volailles sélectionnent leur prise alimentaire en fonction de la taille relative des particules au bec, quelle que soit la composition du régime (Portella et al 1988, Nir et al 1994a, Wauters et al 1997), ce qui peut conduire à un déséquilibre alimentaire dans le cas d'un fort tri particulaire. La granulation, par son action de compactage, permet d'améliorer l'efficacité de la prise alimentaire par le bec chez le poulet à croissance rapide (Nir et al 1994a et b, Quentin et al 2004, Svihus et al 2004). Les poulets de chair ajustent leur préhension en moins de 10 minutes, après un changement de la taille d'aliments (farine et granulé) de même composition (Quentin et al 2004). Chez le dindonneau, le changement de forme de l'aliment, avec le passage de miettes à des granulés, entraîne une diminution immédiate, mais temporaire de l'ingestion avec une augmentation des comportements exploratoires (Lecuelle et al 2010a). La mesure de la durabilité de l'aliment, réalisée classiquement dans les usines, permet d'apprécier la capacité des granulés à résister à l'abrasion et d'estimer ainsi le pourcentage de fines particules susceptibles d'être observées dans les mangeoires.

En ce qui concerne les propriétés mécaniques des aliments, des mesures de dureté sont réalisées en soumettant le granulé à un test de compression. Il peut être ainsi mesuré la force maximale à l'écrasement (en $\mathrm{N}$ ou en $\mathrm{MPa}$ ). Des granulés «durs» $(0,77 \mathrm{MPa})$ sont consommés plus rapidement que des granulés plus tendres $(0,45 \mathrm{MPa})$, pourtant de même taille (Picard et al 1997). Néanmoins cette forte dureté reste toutefois à des valeurs peu élevées. Une plus forte dureté obtenue par une double granulation de l'aliment induit d'ailleurs une baisse d'ingestion (Nir et al 1994b). Un autre critère pouvant être mesuré par le test de compression est la rigidité maximale de la particule (N/mm). Laviron et al (2010) observent chez le dindonneau, une réduction immédiate de la consommation alimentaire lors du passage d'un granulé tendre à un granulé plus rigide de même taille. L'intensité de la baisse de consommation est corrélée à la rigidité de la particule $\left(\mathrm{r}^{2}=0,95\right)$ et plus faiblement à la force maximale à la rupture $\left(r^{2}=0,70\right)$. La mesure de la rigidité des particules comparée à la force maximale à la rupture, représente probablement plus précisément ce que ressent l'oiseau lors de la prise de la particule avec son bec. Des recherches sont nécessaires pour préciser l'effet, sur la rigidité des particules, de la nature des matières premières et du process mis en jeu. Par ailleurs, il est important de mettre en relation l'effet de la dureté avec la taille des particules car un granulé dur sera d'autant moins consommé qu'il sera long. Un autre critère probablement important à considérer est la rugosité des particules. Pour exemple, le grain de blé particulièrement dur mais lisse, est très bien consommé. L'appréciation des angularités des particules, indicatrices de la rugosité des aliments est une voie à explorer.

\section{d) Le goût}

De manière générale, le goût joue un rôle important dans le comportement alimentaire en déterminant si «l'aliment» est nutritif et peut être ingéré, ou 
est potentiellement toxique et doit être rejeté. Chez l'oiseau, la perception gustative est limitée du fait de l'absence de mastication. Les poulets sont toutefois capables de détecter différentes saveurs (umami, sucré, acide, salé et amer), et consomment les aliments dans un ordre décroissant de préférence : l'aspartame (incorporé à $0,13 \%$ ), puis la saccharine $(0,06 \%)$, l'acide citrique $(6 \%)$, le sel $(5 \%)$, et la quinine $(0,10 \%)$ (Balog et Millar 1989). Des goûts marqués peuvent donc modifier le comportement alimentaire, mais il est souvent difficile dans la pratique de dissocier le goût de l'odeur perçue lors de l'ingestion d'un aliment (Picard et al 2000).

\section{2 / Les apprentissages alimen- taires}

Les volailles sont capables de différents types d'apprentissage, par association de sensorialités entre elles ou avec les effets post-ingestifs de l'aliment. Ces informations sont stockées dans la mémoire à long terme et sont réutilisées par l'animal, qui est alors capable d'anticiper les effets d'un aliment qu'il apprend à identifier. Ces apprentissages, permettant à l'animal une meilleure adaptation à son environnement en améliorant sa capacité de choix, interfèrent alors avec les mécanismes de régulation de la prise alimentaire.

\section{a) La mémoire}

La mémoire est la faculté permettant de stocker, conserver et rappeler des expériences ou informations passées. De nombreux travaux ont été réalisés sur la base d'un test d'évitement passif où un poussin exposé à une perle de couleur enduite d'une substance amère, apprend à éviter ensuite le picorage de cette perle (Rose 1991). Il a pu ainsi être montré qu'après la phase d'acquisition, la mémoire se subdivise en trois phases : la mémoire à court terme, la mémoire intermédiaire et la mémoire à long terme.

Un modèle de mémoire a été établi à partir d'un test d'aversion conditionné, en associant une bille de couleur donnée à une substance amère. Un entraînement très renforcé (forte amertume) engendre une mémorisation à long terme, alors que cette dernière n'est pas obtenue avec un entraînement faiblement renforcé (faible amertume). Les transitions entre les trois phases de mémorisation apparaissent exactement à 15 et $55 \mathrm{~min}$ chez le poussin (Gibbs 2008) ou les sujets un peu plus âgés (15 jours) (Atkinson et al 2003).

A partir d'une situation ou expérience donnée, l'apprentissage commence par la délivrance d'informations au cerveau, d'origines visuelle, olfactive, tactile ou auditive. Le processus de mémorisation apparaît durant des séquences bien définies d'étapes en cascades dans différentes zones du cerveau (Gibbs 2008). Chez le poussin, la mémoire à court terme permet de retenir et de réutiliser une quantité limitée d'informations et n'entraîne pas de modifications synaptiques (Rose 1996), tandis que la mémoire à long terme apparaît lorsqu'une information contenue dans la mémoire à court terme y est entreposée via un processus de répétition. Elle requiert des modifications synaptiques, structurelles du cerveau, nécessitant la synthèse de nouvelles protéines. $\mathrm{Ce}$ phénomène appelé la consolidation (Rose 1996), apparaît plus facilement chez le poussin que chez le poulet plus âgé (Turro-Vincent 1994).

Différents peptides jouent un rôle dans l'attention, l'apprentissage, la mémoire et les processus de renforcements. La CCK notamment intervient dans la consolidation de la mémoire d'un régime alimentaire chez les volailles. Chez la jeune caille, le blocage des récepteurs de la CCK situés au niveau digestif inhibe la mémorisation de la consommation d'un nouvel aliment coloré en bleu (Berthelot et al 1996). La CCK étant sécrétée au début de la digestion, il peut en être déduit que la mémoire de l'aliment est précoce, même si des renforcements d'origine métabolique peuvent moduler ensuite l'impression laissée à l'animal.

\section{b) Nature des apprentissages}

La mémoire permet aux volailles de développer des apprentissages orientant les choix alimentaires. Différents types d'apprentissage sont répertoriés, d'origine céphalique (visuels, tactiles et olfacto-gustatifs) ou dépendant de conséquences post-ingestives.

- Apprentissages visuels, tactiles et olfacto-gustatifs

Le poussin est capable d'éviter une bille colorée s'il connaissait préalablement cette bille enduite d'une substance amère (Rose 1991). Cet apprentissage est plus marqué lorsque la bille présente une combinaison de couleurs (noire et jaune) plutôt qu'une seule couleur (noire ou jaune) (Johnston et Burne 2008). Le poussin peut donc associer des sensorialités visuelle et gustative, et ceci d'autant plus que la couleur est discriminante.

Le comportement de picorage est un autre exemple du rôle de l'expérience sur des modifications des préférences de base. Des poussins à qui plusieurs types de graines sont proposés, préfèrent tout d'abord le sorgho et $24 \mathrm{~h}$ après, des graines plus petites. En revanche, des poussins dont la pointe du bec a été coupée, capables de ce fait d'avaler de plus grosses graines que les autres, maintiennent leur préférence (Hausberger 1992a). Si les graines sont collées au sol, et ne peuvent donc être avalées, lors d'un second test réalisé $24 \mathrm{~h}$ après, la préférence initiale pour le sorgho est reportée vers d'autres graines (millet blanc et japonais) chez les poussins débecqués ou non (Hausberger 1992b). La possibilité d'avaler l'item préféré visuellement peut donc être un facteur déterminant si l'expérience doit renforcer ou modifier les préférences visuelles.

Le poussin est également capable d'apprentissage lors d'associations d'odeur et de goût : il évite une solution d'eau parfumée à l'amande lorsque cette dernière a été préalablement mélangée à de la quinine (Roper et Marples 1997). Par ailleurs, les poussins peuvent se familiariser précocement, pendant les deux derniers jours d'incubation et au moment de l'éclosion, à une odeur spécifique (huile essentielle d'orange) : comparés à des poussins non stimulés, les poussins approchent plus rapidement et passent plus de temps près des boîtes dont l'une a été odorisée à l'orange et l'autre non (Porter et Picard 1998). De même, des poussins exposés pendant l'incubation à une odeur passent plus de temps après l'éclosion à consommer l'aliment portant l'odeur connue, tandis qu'à plus long terme ( 8 jours), ils la rejettent, indiquant un effet à long terme de l'expérience lors de l'incubation sur le comportement alimentaire ultérieur (Bertin et al 2010).

- Apprentissages aversifs et appétitifs liés aux conséquences post-ingestives

D'autres cas sont décrits, où l'animal associe les sensorialités de l'aliment aux conséquences post-ingestives. Cette association peut être de type aversif lorsque les conséquences sont négatives, ou appétitive lorsqu'elles sont positives.

\section{c) L'aversion alimentaire conditionnée}

Dans le cas d'aversion alimentaire conditionnée, l'association d'un aliment à un malaise gastrique engendre une mémoire aversive à long terme. Le poussin est capable d'associer spécifiquement le fait de manger à l'apparition d'un malaise, et ce, très rapidement après l'éclosion (Hale et Green 1988). Des poulets exposés brièvement à une nouvelle odeur (orange) puis recevant une injection de $\mathrm{LiCl}$ induisant un malaise, montrent ensuite un fort refus de l'aliment sentant l'orange, contrairement aux animaux ayant eu une injection de sérum physiologique (Turro et al 1994). Il est ainsi suggéré 
que le poulet apprend à reconnaître des odeurs spécifiques associées à des conséquences négatives, et qu'il est capable d'adapter son comportement alimentaire en fonction de ces odeurs pour optimiser l'ingestion de substances appropriées. Le signal olfactif semble plus efficace que le goût (Turro-Vincent 1994), ou la couleur (Roper et Marples 1997) pour former une aversion conditionnée chez de jeunes poussins. Chez le poulet plus âgé (4 semaines), il est difficile d'obtenir une aversion conditionnée avec un seul signal, l'odeur ou l'aspect, mais la combinaison des deux renforce l'effet (Turro-Vincent 1994). Le poulet plus âgé aurait besoin de plus d'indications que le poussin pour reconnaître son aliment. Par ailleurs, l'aversion conditionnée basée sur une association couleur - malaise $(\mathrm{LiCl})$ n'est pas retenue plus d'une semaine (Hayne et al 1996). Le retour de la consommation de l'aliment coloré, initialement toxique, semble correspondre à une réponse adaptative : les animaux qui excluraient unilatéralement une source alimentaire sur la base d'un unique contact avec un aliment coloré, prendraient le risque d'occulter sur le long terme, de possibles sources alimentaires (Hayne et al 1996). Il semble qu'il en soit de même avec les apprentissages liés à l'odeur.

Dans le cas d'un aliment particulièrement déséquilibré en un acide aminé, un mécanisme de détection de ces déséquilibres alimentaires permet de déclencher rapidement chez le rat une réponse comportementale de rejet de l'aliment. Ce phénomène représenterait un mécanisme protecteur évitant les effets métaboliques délétères d'une ingestion en trop grande quantité d'un régime disproportionné en AAE (Gietzen et Magrum 2001). La capacité de refuser un aliment déséquilibré en acides aminés procure un avantage à l'animal, en lui permettant de privilégier une nourriture équilibrée et mieux adaptée à ses besoins. Chez le rat, des travaux anciens avaient déjà révélé le rôle du cortex piriforme antérieur, dans la mise en place de l'aversion visà-vis de régimes déséquilibrés en acides aminés (Leung et Rogers 1971). Cette zone est capable de détecter la forte diminution de la concentration sanguine en un acide aminé consécutive à la consommation d'un régime carencé. Les rongeurs peuvent détecter des déficiences en acides aminés et modifier leur comportement alimentaire en seulement 20 minutes (Gietzen et Rogers 2006). Chez le poulet, le cortex piriforme semble impliqué comme chez le rat pour ces mêmes fonctions (Firman et Kuenzel
1988). Comme les rongeurs, les poulets réagissent à des déficits en acides aminés indispensables en un temps rapide. A 8 jours d'âge, des poulets recevant un aliment déficient en lysine, méthionine et tryptophane $(-45 \%)$ réduisent leur ingestion de $60 \%, 6 \mathrm{~h}$ après le changement d'aliment (Picard et al 1993). Avec l'alternance d'aliments à teneur réduite et normale en lysine, dans la journée, les poulets de chair apprennent à reconnaître les aliments et adaptent leur ingestion en fonction de l'aliment reçu (Bizeray et al 2002).

\section{d) L'apprentissage appétitif}

A l'opposé des cas d'aversion alimentaire conditionnée préalablement décrits, l'association d'un aliment à des conséquences post-ingestives positives augmente l'acceptation de cet aliment. On parle alors de préférence conditionnée ou d'apprentissage appétitif. Des rats entraînés à consommer une solution présentant une flaveur particulière, couplée à une infusion glucidique intragastrique, préfèrent ensuite cette solution (Sclafani 2001). Les effets post-ingestifs d'un aliment lipidique comparé à un aliment glucidique isocalorique, stimulent plus la consommation chez le rat et conditionnent une plus forte préférence pour la flaveur utilisée (Lucas et al 1998). Ceci semble lié à un moindre effet satiétogène des lipides avec toutefois un renforcement post-ingestif. Les proportions relatives d'acides gras polyinsaturés (élevée) et saturés (basse) augmentent le renforcement chez le rat (Ackroff et al 2005). De tels résultats n'ont pas été décrits à notre connaissance chez les oiseaux. Il peut toutefois être supposé que des mécanismes similaires puissent opérer.

Dans plusieurs situations, la volaille est capable de faire l'association entre des caractéristiques de l'aliment et des effets post-ingestifs positifs. Un attrait particulier pour les aliments les plus riches en protéines (soja) plutôt que pour les céréales, est observé chez le poussin après $24 \mathrm{~h}$ de consommation (Turro-Vincent 1994). Le poussin nouveau-né fait, pendant les premières heures, un choix basé sur ses préférences spontanées, puis le modifie progressivement, suite au renforcement post-ingestif pour l'adapter aux besoins de son organisme (Yo 1996).

Différents travaux ont été réalisés avec l'alimentation séquentielle, qui consistait à distribuer alternativement aux animaux un jour sur deux, deux aliments de caractéristiques différentes (énergie, protéines). Ce système d'alimentation représente un paradigme intéressant pour mieux comprendre le déterminisme de la prise alimentaire. Les animaux confrontés successivement à des aliments déséquilibrés nutritionnellement, voient leur état métabolique modifié au cours du temps. De plus, la modification des apports en énergie et en protéines modifie en général également les caractéristiques sensorielles des aliments. Ainsi, des travaux ont été menés sur des poulets de chair à croissance rapide avec des alternances d'aliments différant par leurs caractéristiques énergétiques et/ou protéiques. Avec des changements d'aliment toutes les $24 \mathrm{~h}$, la consommation à l'échelle de l'heure et de la journée, est clairement dépendante de la teneur énergétique de l'aliment. Le poulet privilégie l'aliment le plus énergétique et ne semble pas détecter facilement un aliment à faible ou forte teneur en protéines (Bouvarel et al 2008a) (figure 3). Ces adaptations sont progressives, ce qui suggère qu'il existe un effet de l'expérience sur la consommation. Il a ainsi été montré que les poulets apprennent à reconnaître les aliments riche ou pauvre en énergie, tandis qu'il n'est pas clairement mis en évidence d'apprentissage vis-à-vis des aliments variant par leur teneur en protéines. La préférence de poulets naïfs est dirigée vers l'aliment le moins énergétique puis évolue vers le plus énergétique (Bouvarel et al 2008b) (figure 4). Des interactions entre les propriétés nutritionnelles et sensorielles des aliments sont certainement à l'origine de ces observations. Toutefois, même si le poulet exprime une préférence pour l'aliment le plus dur, la reconnaissance de l'aliment le plus énergétique ne repose pas uniquement sur cette caractéristique (Bouvarel et al 2009).

D'autres expériences ont été menées avec des alternances d'aliments carencés ou non en acides aminés indispensables. Comparée à une alimentation continue, le temps d'ajustement de la consommation devient plus rapide : après quelques jours d'adaptation, l'ingestion est modifiée dès la première heure (Picard et al 1994). Il en est de même en situation de choix quand l'aliment carencé est connu (Picard et al 1993). Ces ajustements précoces sont d'autant plus marqués que la carence du régime est forte ou longue (Perrot 2005). Si un changement d'aspect, de composition, est associé au changement d'équilibre en acides aminés, les réactions de la première heure sont encore amplifiées (Picard et al 1994). L'animal doit pouvoir jauger les propriétés sensorielles de l'aliment pour adapter son ingestion (Forbes et Shariatmadari 1996). La volaille est ainsi capable d'anticiper les effets métaboliques d'un aliment qu'elle apprend à identifier. 
Figure 3. Quantité quotidienne d'aliment ingéré de poulets soumis à une alimentation continue (Témoin) comparée à une alimentation séquentielle à compter de 10 jours d'âge, avec une alternance d'aliments variant a) en énergie (E- et $E+)$ : distribution de l'aliment le moins énergétique et du plus énergétique, un jour sur deux, b) en protéines $(P+$ et $P$-) : distribution de l'aliment le plus protéique et du moins énergétique, un jour sur deux (Bouvarel et al 2008a).

a) Energie

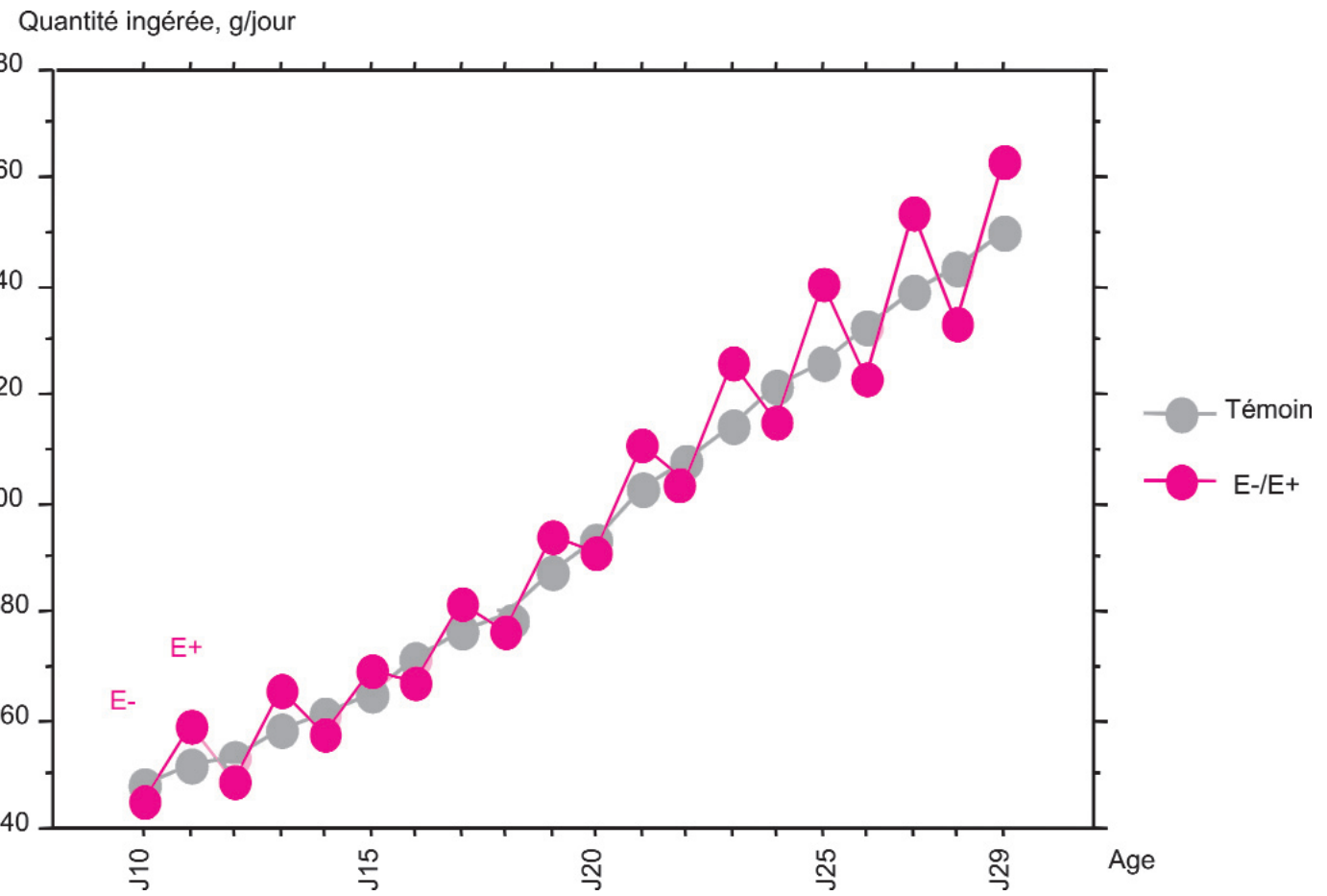

Le principe de l'alimentation séquentielle repose sur une distribution cyclique de deux aliments de composition nutritionnelle et éventuellement de forme différente. Ce mode d'alimentation est une solution envisagée pour réduire le coût alimentaire et pour améliorer le bien-être animal (troubles locomoteurs).

b) Protéines

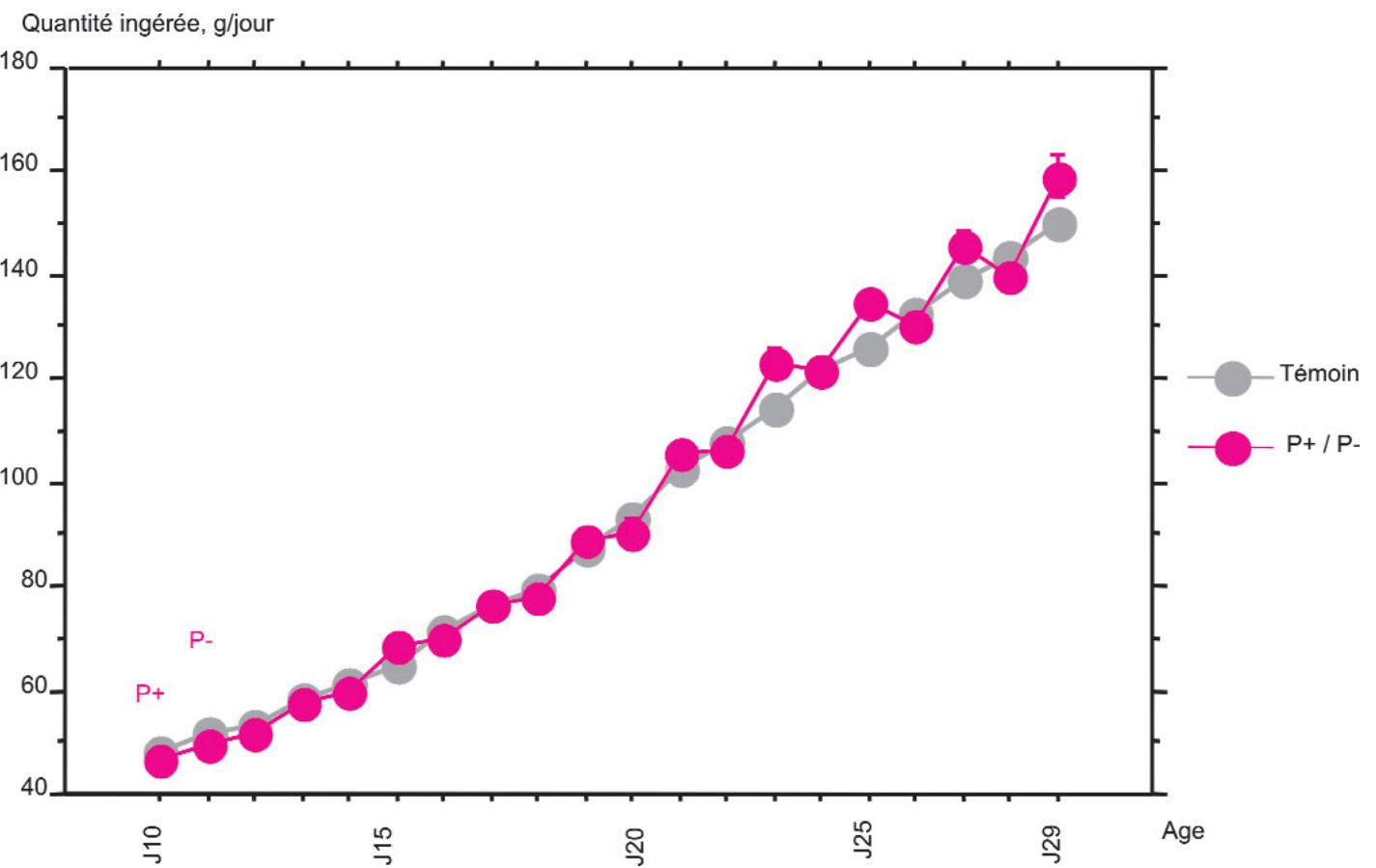

Le principe de l'alimentation séquentielle repose sur une distribution cyclique de deux aliments de composition nutritionnelle et éventuellement de forme différente. Ce mode d'alimentation est une solution envisagée pour réduire le coût alimentaire et pour améliorer le bien-être animal (troubles locomoteurs). 
Figure 4. Des poulets disposent en libre-choix de deux aliments de concentration énergétique différente (E- et E+). Les poulets naïfs ne connaissaient pas les aliments avant le test tandis que les poulets expérimentés avaient reçu préalablement, alternativement d'un jour à l'autre, les aliments $E$ - et E+ pendant 8 jours. Le pourcentage de la quantité d'aliment E+ ingérée est mesurée après 15 min de test (d'après Bouvarel et al 2008b).

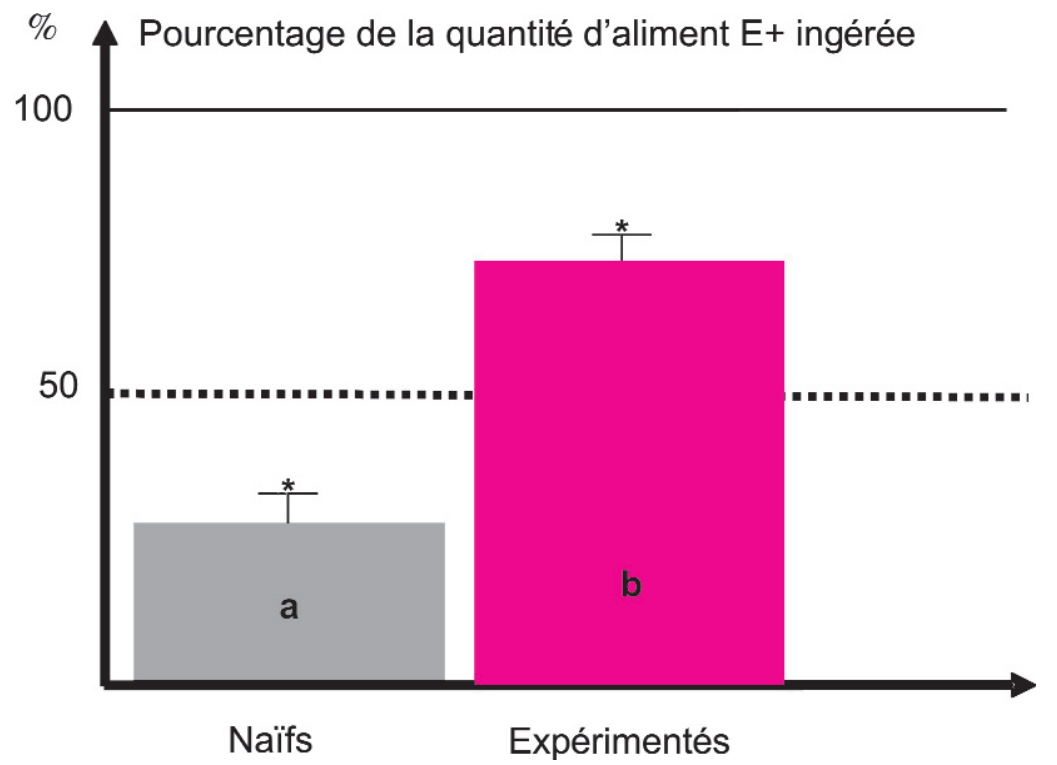

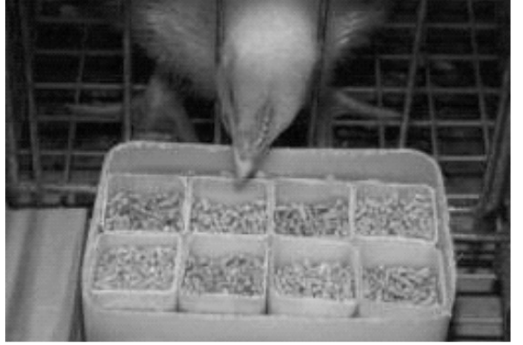

Alimentation en libre choix

Les barres portant un * sont significativement différentes de $50 \%$ (Wilcoxon, $\mathrm{P}<0,05$ ) signifiant une préférence pour E+ si $>50 \%$ ou $\mathrm{E}$ - si $<50 \%$. Les barres avec des lettres différentes sont significativement différentes (Mann-Withney, $P<0,05$ ).

\section{Conclusion}

La «machine» biologique corporelle permet d'assurer la préservation d'une homéostasie générale mise en œuvre sous la forme d'un équilibre dynamique. La prise alimentaire est guidée par des facteurs sensoriels, digestifs et métaboliques qui interviennent succes- sivement et peuvent interagir, et l'animal est capable «d'apprendre» pour s'adapter à son environnement. Ceci est d'autant plus développé que la volaille est soumise à une alimentation complexe. Or dans la pratique, les poulets de chair reçoivent généralement au fil du temps des aliments souvent agglomérés, adaptés en taille et en composition, à leur stade physiologique, sans que soit considérée la sensorialité de l'aliment. La prise en compte, dans les plans d'alimentation futurs, des préférences alimentaires et des capacités d'apprentissage des volailles, constitue un challenge ambitieux pour les nutritionnistes pour améliorer la durabilité de la production.

\section{Références}

Ackroff K., Lucas F., Sclafani A., 2005. Flavor preference conditioning as a function of fat source. Physiol. Behav., 85, 448-460.

Amerah A.M., Ravindran V., Lentle R.G.,Thomas D.G., 2007. Influence of feed particle size and feed form on the performance, energy utilization, digestive tract development, and digesta parameters of broiler starters. Poult. Sci., 86, 2615-2623.

Ashwell C., Czerwinski S.M., Brocht D.M. McMurty J.P., 1999. Hormonal regulation of leptin expression in broiler chickens. Am. J. Physiol., 276, R226-R232.

Atkinson R., Bevilaqua L.R.M., Rostas J.A.P., Huntera G., 2003. Discriminative taste aversion learning: A learning task for older chickens. Neurobiology of Learning and Memory 79, 25-31.

Balog J.M., Millar R.I., 1989. Influence of the sense of taste on broiler chick feed consumption. Poult. Sci., 68, 1519-1526.

Bensaïd A., Tomé D., L'Heureux-Bourdon D., Even P., Gietzen D., Morens C., Gaudichon
C., Larue-Achagiotis C., Fromentin G., 2003. A high-protein diet enhances satiety without conditioned taste aversion in the rat. Physiol. Behav., 78, 311-320.

Berthelot V., Belzung C., Meunier-Salaün M.C., Nowak R., Novak M.P., 1996. Cholecystokinin A receptor antagonist inhibits feed memory in Japanese quail. Physiol. Behav., 60, 575-579.

Bertin A., Calandreau L., Arnould C., Nowak R., Levy F., Noirot V., Bouvarel I., Leterrier C., 2010. In Ovo olfactory experience influences post-hatch feeding behaviour in young chickens. Ethology, 116, 1-11.

Bizeray D., Leterrier C., Constantin P., Picard M., Faure J.M., 2002. Sequential feeding can increase activity and improve gait score in meattype chickens. Poult. Sci., 81, 1798-1806.

Blundell J.E.,1991. Pharmacological approaches to appetite suppression. Trends Pharmacol. Sci., 12, 147-157.

Bogatyrev S., Tzschentke B., Yakimova K., 2010. Influence of leptin on hypothalamic neu- rons controlling food intake and body weight in chicken. XIII ${ }^{\text {th }}$ Eur. Poultr. Conf., 23-27 August 2010, Tours, France, 739.

Bokkers E.A.M., Koene P., 2003. Eating behaviour, and prepandial and postprandial correlations in male broiler and layer chickens. Brit. Poult. Sci., 44, 538-544.

Bouvarel I., Chagneau A.M., Lescoat P., Tesseraud S., Leterrier C., 2008a. Forty-eighthour cycle sequential feeding with diets varying in protein and energy contents: adaptation in broilers at different ages. Poult. Sci., 87, 196-203.

Bouvarel I., Vallée C., Chagneau A.M., Constantin P., Lescoat P., Ferreira G., Leterrier C., 2008b. Effects of various energy and protein levels during sequential feeding on feed preferences in meat-type chickens. Animal, 2, 1674-1681.

Bouvarel I., Chagneau A.M., Lecuelle S., Lescoat P., Ferreira G., Duvaux-Ponter C., Leterrier C., 2009. Feed composition and hardness interact in preference and intake in chickens. Appl. Anim. Behav. Sci., 118, 162-168. 
Bregendahl K., Sell J.L.,Zimmerman D.R., 2002. Effect of low-protein diets on growth performance and body composition of broiler chicks. Poult. Sci., 81, 1156-1167.

Bungo T., Shimojo M., Masuda Y., Tachibanab T., Tanaka S.J., Sugahara K., Furuse M., 1999. Intracerebroventricular administration of mouse leptin does not reduce food intake in the chicken. Brain Res., 817, 196-198.

Burkhardt D., 1982. Birds, berries and UV. A note on some consequences of UV vision in birds. Naturwissenschaften, 69, 153-157.

Burne T.H., Rogers L.J., 1996. Responses to odorants by the domestic chick. Physiol. Behav., 60, 1441-1447.

Buyse J., Adelsohn D.S., Decuypere E., Scanes C.G., 1993. Diurnal-nocturnal changes in food intake, gut storage of ingesta, food transit time and metabolism in growing broiler chickens: a model for temporal control of energy balance. Brit. Poult. Sci., 34, 699-709.

Carré B., 2000. Effets de la taille des particules alimentaires sur les processus digestifs chez les oiseaux d'élevage. INRA Prod. Anim., $13,131-136$

Cassy S., Dridi S.M.P., Taouis M., 2001. La leptine chez le poulet. INRA Prod. Anim., 14, 161-169.

Cassy S., Dridi S.M.P., Crochet S., Derouet M., Keisler D.H., Taouis M., 2004. Peripheral leptin effect on food intake in young chickens is influenced by age and strain. Dom. Anim. Endocrinol., 27, 51-61.

Chagneau A.M., Bessonneau D., Bouchot C., Lescoat P., Picard M., Lessire M., 2006. Broiler short-term feed preferences measured with srabox, a new feed choice procedure. Poult. Sci., 85, 808-815.

Chaplin S.B., Raven J., Duke G.E., 1992. The influence of the stomach on crop function and feeding behavior in domestic turkeys. Physiol. Behav., 52, 261-266.

Chen L.L., Jiang Q.Y., Zhu X.T., Shu G., Bin Y.F., Wang X.Q., Gao P., Zhang Y.L., 2007. Ghrelin ligand-receptor mRNA expression in hypothalamus, proventriculus and liver of chicken (Gallus gallus domesticus): studies on ontogeny and feeding condition. Comp. Biochemist. Physiol. Part A, Mol. Integrative Physiol., 147, 893-902.

Clayton D.A., 1978. Socially facilitated behavior. Quart. Rev. Biol., 53, 373-392.

Collier G., Johnson D.F., 2004. The paradox of satiation. Physiol. Behav., 82, 149-153.

Collin A., Joubert R., Swennen Q., Damon M., Métayer-Coustard S., Skiba-Cassy S., Evaraert N., Buyse J., Tesseraud S., 2009. Involvement of thyroid hormones in the regulation of mitochondrial oxidations in mammals and birds. In: thyroid hormones: functions, related diseases and uses. Kuehn F.S., Lozada M.P. (Eds), Nova Biomed., 1, 93-107.

Collins L.M., Sumpter D.J.T., 2007. The feeding dynamics of broiler chickens. J. Royal Soc. Interface, 4, 65-72.

De Basilio V., Picard M., 2002. La capacité de survie des poulets à un coup de chaleur est augmentée par une exposition précoce à une température élevée. INRA Prod. Anim., 15, 235-245.

Denbow D.M., 1994. Peripheral regulation of food intake in poultry. J. Nutr., 124 (Suppl. 8), 1349S-1354S.
Denbow D.M., Meade S., Robertson A., McMurtry J.P., Richards M., Ashwell C., 2000. Leptin-induced decrease in food intake in chickens. Physiol. Behav., 69, 359-362.

Dharmaretnam M., Rogers L.J., 2005. Hemispheric specialization and dual processing in strongly versus weakly lateralized chicks. Behav. Brain Res., 162, 62-70.

Dridi S., Raver N., Gussakovsky E.E., Derouet M.M.P., Gertler A., Taouis M., 2000. Biological activities of recombinant chicken leptin C4S analog compared with unmodified leptins. Am. J. Physiol., 279, E116-E123.

Dridi S., Swennen Q., Decuypere E., Buyse J., 2005. Mode of leptin action in chicken hypothalamus. Brain Res., 1047, 214-223.

Dridi S., Temim S., Derouet M., Tesseraud S., Taouis M., 2008. Acute cold- and chronic heat-exposure upregulate hepatic leptin and muscle uncoupling protein (UCP) gene expression in broiler chickens. J. Exp. Zool., Part A, Ecol. Genet. Physiol., 309, 381-388.

Duchamp C., Cohen-Adad F., Rouanet J.L., Barré H., 1992. Histochemical arguments for muscular non-shivering thermogenesis in muscovy ducklings. J. Physiol., 457, 27-45.

Emmerton J., 1983. Pattern discrimination in the near-ultraviolet by pigeons. Perception Psychophys., 34, 555-559.

Fancher B.I., Jensen L.S., 1989. Dietary protein level and essential amino acid content: influence upon female broiler performance during the grower period. Poult. Sci., 68, $897-$ 908.

Ferrando C., Vergara P., Jimenez M., Gonalons E., 1987. Study of the rate of passage of food with chromium-mordanted plant cells in chickens (Gallus gallus). Quart. J. Exp. Physiol. 72, 251-259.

Firman J.D., Kuenzel W.J., 1988. Neuroanatomical regions of the chick brain involved in monitoring amino deficient diets. Brain Res. Bull., 21, 637-642.

Flynn M.C., Scott T.R., Pritchard T.C., Plata-Salamán C.R., 1998. Mode of action of OB protein (leptin) on feeding. Am. J. Physiol., 275, R174-R179.

Forbes J.M., Shariatmadari F., 1996. Shortterm effects of food protein content on subsequent diet selection by chickens and the consequences of alternate feeding of high- and low-protein foods. Brit. Poult. Sci., 37, 597607.

Furuse M.T., Tachibana T., Ohgushi A., Ando R., Shimojo M., Masuda Y., 2001. Intracerebroventricular injection of ghrelin and growth hormone releasing factor inhibits food intake in neonatal chicks. Neurosci. Lett., 301, 123-126.

Geelissen S.M., Swennen Q., Geyten S.V., Kuhn E.R., Kaiya H., Kangawa K., Decuypere E., Buyse J., Darras V.M., 2006. Peripheral ghrelin reduces food intake and respiratory quotient in chicken. Dom. Anim. Endocrinol., $30,108-116$.

Gentle M.J., Breward J., 1986. The bill tip organ of the chicken. J. Anat., 145, 79-85.

Geraert P.A., 1991. Métabolisme énergétique du poulet de chair en climat chaud. INRA Prod. Anim., 4, 256-267.

Gibbs M.E., 2008. Memory systems in the chick: Regional and temporal control by noradrenaline. Brain Res. Bull., 76, 170-182.
Gietzen D.W., Magrum L.J., 2001. Molecular mechanisms in the brain involved in the anorexia of branched-chain amino acid deficiency. J. Nutr., 131, 851S-855S.

Gietzen D.W., Rogers Q.R., 2006. Nutritional homeostasis and indispensable amino acid sensing : a new solution to an old puzzle. Neurosci., 29, 91-99.

Hale C., Green L., 1988. Effects of early ingestional experiences on the acquisition of appropriate food selection by young chicks. Anim. Behav., 36, 211-224.

Hausberger M., 1992a. Visual pecking preferences in domestic chicks. Part I. Responses of different breeds of chicks to different sorts of seeds. C.R Acad. Sci., Série III, 314, 273278.

Hausberger M., 1992b. Visual pecking preferences in domestic chicks. Part II. The role of experience in their maintenance or not. C.R Acad. Sci., Série III, 314, 331-335.

Hayne H., Rovee-Collier C., Collier G., Tudor L., Morgan C.A., 1996. Learning and retention of conditioned aversions by freely feeding chicks. Dev. Psychobiol., 29, 417-431.

Howie J.A., Tolkamp B.J., Avendano S. Kyriazakis I., 2009a. A novel flexible method to split feeding behaviour into bouts. Appl. Anim. Behav. Sci., 116, 101-109.

Howie J.A., Tolkamp B.J., Avendano S., Kyriazakis I., 2009b. The structure of feeding behavior in commercial broiler lines selected for different growth rates. Poult. Sci., 88, 1143 1150 .

Jensen J., 2001. Regulatory peptides and control of food intake in non-mammalian vertebrates. Comp. Biochem. Physiol., Part A, Mol. Integrative Physiol., 128, 471-479.

Johnston A.N.B., Burne T.H.J., 2008 Aposematic colouration enhances memory formation in domestic chicks trained in a weak passive avoidance learning paradigm. Brain Res. Bull., 76, 313-316.

Jones R.B., Roper T.J., 1997. Olfaction in the domestic fowl: a critical review. Physiol. Behav., 62, 1009-1018.

Kaya H., Darras V.M., Kangawa K., 2007. Ghrelin in birds: its structure, distribution and function. J. Poult. Sci., 44, 1-18.

Kuenzel W.J., 1994. Central neuroanatomical systems involved in the regulation of food intake in birds and mammals. J. Nutr., 124 (8 Suppl.), 1355S-1370S.

Laviron F., Chagneau A.M., Lecuelle S., Lescoat P., Leterrier C., Bouvarel I., 2010. Pellet hardness effects short-term intake during diet change-over in turkeys. 24-26 August, $13^{\text {th }}$ Eur. Poult. Congr., Tours, France, Poster Session 1.

Lecuelle S., Bouvarel I., Chagneau A.M., Lescoat P., Laviron F., Leterrier C., 2010a. Feeding behaviour in turkeys with a changeover from crumbs to pellets. Appl. Anim. Behav. Sci., 125, 132-142.

Lecuelle S., Bouvarel I., Chagneau A.M., Laviron F., Lescoat P., Leterrier, C., 2010b. Early visual experience of food does not appear to reduce subsequent feed neophobia in turkey. Poult. Sci., accepté.

Leung P.M.B., Rogers Q.R., 1971. Importance of prepyriform cortex in foodintake response of rats to amino acids. Am. J. Physiol., 221, 929-935. 
Lucas F., Ackroff K., Sclafani A., 1998. High-fat diet preference and overeating mediated by postingestive factors in rats. Am. J Physiol., Regulatory, Integrative and Comparative Physiology, 275, 1511-1522.

Mabayo R.T., Okumura J.I., Hirao A., Sugita S., Sugahara K., Furuse M., 1996. The role of olfaction in oil preference in the chicken. Physiol. Behav., 59, 1185-1188.

McMinn J.E., Baskin D.G., Schwartz M.W., 2000. Neuroendocrin mechanisms regulating food intake and body weight. Obesity Rev., 1, $37-46$.

Merckaert J., Vandesande F., 1996. Autoradiographic localization of receptors for neuropeptide Y (NPY) in the brain of broiler and leghorn chickens (Gallus domesticus). J. Chem. Neuroanatom., 12, 123-134.

Moran E.T., 1982. Food seeking. In: Comparative nutrition of fowl and swine, the gastro-intestinal systems. Amazon Co.UK (Ed), M.E.T. University of Guelph, 5-16.

Nielsen B.L.,2004. Behaviour aspects of feeding constraints: do broilers follow their gut feelings? Appl. Anim. Behav. Sci., 86, 251260.

Nir I., Shefet G., Aaroni Y., 1994a. Effect of particle size on performance. 1. Corn. Poult. Sci., 73, 45-49.

Nir I., Twina Y., Grossman E., Nitsan Z., 1994b. Quantitative effects of pelleting on performance, gastrointestinal tract and behaviour of meat-type chickens. Brit. Poult. Sci., 35, 589-602.

Noblet J., Dubois S., van Milgen J. Warpechowski M., Le Bellego L., Carré B., 2007. Influence de la teneur en protéines de l'aliment sur l'utilisation métabolique de l'énergie chez le poulet. Journ. Rech. Avicole, Tours, France, 141-144.

Noy Y., Sklan D., 2002. Nutrient use in chicks during the first week posthatch. Poult. Sci., 81, 391-399.

Osorio D.., Vorobyev M., Jones C.D., 1999. Colour vision of domestic chicks. J. Exp. Biol. 202, 2951-2959.

Perrot P., 2005. Effets de variations de l'apport de lysine lors de programmes d'alimentation séquentielle sur les troubles locomoteurs et la croissance des poulets de chair. Mémoire Ingénieur Ecole Supérieure d'Agriculture d'Angers, France, 56p.

Pesti G.M., Fletcher D.L., 1984. The response of male broiler chickens to diets with various protein contents during the grower and finisher phases. Brit. Poult. Sci., 25, 415-423.

Picard M., Turro I., Launay F., Mills A.D., Meulin J.M., Faure J.M., 1992. Food intake patterns of three week old broilers cages individually or in groups. XIX World's Poultry Congress, Amsterdam, Netherlands, 2, 429. 434.

Picard M., Uzu G., Dunnington E.A., Siegel P.B., 1993. Food intake adjustments of chicks: short term reactions to deficiencies in lysine, methionine and tryptophan. Brit. Poult. Sci., 34, 737-746.

Picard M., Faure J.M., Siegel P.B., Dunnington E.A., Uzu G., Dalibard P., 1994 Food intake and amino acids in poultry. RhônePoulenc Animal Nutrition (Ed). France, 43p.

Picard M., Melcion J.P., Bouchot C., Faure J.M., 1997. Picorage et préhensibilité des parti- cules alimentaires chez les volailles. INRA Prod. Anim., 10, 403-414.

Picard M., Le Fur C., Melcion J.P., Bouchot C., 2000. Caractéristiques granulométriques de l'aliment : le «point de vue» (et de toucher) des volailles. INRA Prod. Anim., 13, 117-130.

Picard M., Melcion J.P., Bertrand D., Faure J.M., 2002. Visual and tactile cues perceived by chickens. In: Poultry feedstuffs: supply, composition and nutritive value. $\mathrm{Mc} \mathrm{Nab}$ and Boorman (Eds), 279-298.

Portella F.J., Caston L.J., Leeson S., 1988. Apparent feed particle size preference by broilers. Can. J. Anim. Sci., 68, 923-930.

Porter R.H., Picard M., 1998. Effects of early odor exposure in domestic chicks. Reprod., Nutr., Dev., 38, 441-448.

Porter R.H., Hepper P.G., Bouchot C., Picard M., 1999. A simple method for testing odo detection and discrimination in chicks. Physiol. Behav., 67, 459-462.

Quentin M., Bouvarel I., Berri C., Le BihanDuval E., Baéza E., Jégo Y., Picard M., 2003. Growth, carcass composition and meat quality response to dietary concentrations in fastmedium- and slow-growing commercial broilers. Anim. Res., 52, 65-77.

Quentin M., Bouvarel I., Picard M., 2004 Short and long term effects of feed form on fast- and slow-growing broilers. J. Appl. Poult. Res., 13, 540-548.

Richard P., Vilarino M., Faure J.M., Leon A., Picard M., 1997. Etude du comportement du poulet de chair dans un élevage tropical au Vénézuela. Rev. Elev. Méd. Vét. Pays Trop. $50,65-74$.

Richards M.P., 2003. Genetic regulation of feed intake and energy balance in poultry. Poult. Sci., 82, 907-916.

Richards M.P., Proszkowiec-Weglarz M. 2007. Mechanisms regulating feed intake, energy expenditure, and body weight in poultry. Poult. Sci., 86, 1478-1490.

Rogers P.J., 1995. The development of the brain and behaviour in the chicken, $\mathrm{CAB}$ Int. Wallingford, UK, 95-110.

Rogers L.J., Zucca P., Vallortigara G., 2004 Advantage of having a lateralized brain. Proc. Biol. Sci., Royal Soc., 271 (Suppl. 6), S420-S422.

Roper T.J., Marples N.M., 1997. Odour and colour as cues for taste-avoidance learning in domestic chicks. Anim. Behav., 53, 1241-1250.

Rose S.P., 1991. How chicks make memories: the cellular cascade from c-fos to dendritic remodelling. Trends Neurosci., 14, 390-397.

Rose S.P., 1996. Cell adhesion molecules and the transition from short- to long-term memory. J. Physiol., 90, 387-391.

Rosebrough R.W., Steele N.C., 1985. Energy and protein relationships in the broiler. 1. Effect of protein levels and feeding regimens on growth, body composition, and in vitro lipogenesis of broiler chicks. Poult. Sci., 64, 119126.

Saito E.S., Kaiya H., Takagi T., Yamasaki I. Denbow D.M., Kangawa K., Furuse M., 2002. Chicken ghrelin and growth hormone-releasing peptide-2 inhibit food intake of neonatal chicks. Eur. J. Pharmacol., 453, 75-79.

Saito E.S., Kaiya H., Tachibana T. Tomonaga S., Denbow D.M., Kangawa K.
Furuse M., 2005. Inhibitory effect of ghrelin on food intake is mediated by the corticotropinreleasing factor system in neonatal chicks. Regulatory Peptides, 125, 201-208.

Sauvant D., Bastianelli D.,Van Milgen J., 1995. Systèmes d'unité d'alimentation et lois de réponse du porc aux régimes alimentaires. Journ. Rech. Porcine Fr., 27, 237-244.

Savory C.J., 1979. Feeding behaviour. In: Food intake regulation in poultry. Boorman K.N, Freeman B.M. (Eds). Edinburgh, UK, 277-323.

Savory C.J., 1985. An investigation into the role of the crop in control of feeding in Japanese quail and domestics fowls. Physiol. Behav., 35, 917-928.

Savory C.J., 1999. Temporal control of feeding behaviour and its association with gastrointestinal function. J. Exp. Zool., 283, 339-347.

Sclafani A., 2001. Post-ingestive positive controls of ingestive behavior. Appetite, 36, 79-83.

Sharp P.J., Dunn I.C., Waddington D. Boswell T., 2008. Chicken leptin. Gener. Comp. Endocrinol., 158, 2-4.

Shelton J.L., Dean D.W., Southern L.L., Bidner T.D., 2005. Effect of protein and energy sources and bulk density of diets on growth performance of chicks. Poult. Sci., 84, 1547 1554.

Shires A., Thompson J.R., Turner B.V., Kennedy P.M., Goh Y.K., 1987. Rate of passage of corn-canola meal and corn-soybean meal diets through the gastrointestinal tract of broiler and white leghorn chickens. Poult. Sci., 66, 289-298

Sklan D., Dukbrov D., Eisner U., Hurwitz S., 1975. 51Cr-EDTA, 91Y and 141Ce as nonabsorbed reference substances in the gastrointestinal tract of the chicken. J. Nutr., 105, 1549 1552

Smith E.R., Pesti G.M., 1998. Influence of broiler strain cross and dietary protein on the performance of broilers. Poult. Sci., 77, 276 281.

Stubbs R.J., Prentice A.M., James W.P. 1997. Carbohydrates and energy balance. Ann. N.Y. Acad. Sci., 819, 44-69.

Svihus B., 2007. Improving nutritional value through feed technology. ESPN 2007, Strasbourg, France, 431-436.

Svihus B., Kløvstada K.H., Pereza V., Zimonjaa O., Sahlströmb S., Schüllerc R.B. Jeksrudd W.K., Prestløkkene E., 2004 Physical and nutritional effects of pelleting of broiler chicken diets made from wheat ground to different coarsenesses by the use of roller mill and hammer mill. Anim. Feed Sci. Technol., 117, 281-293.

Swennen Q., Decuypere E., Buyse J., 2007. Implications of dietary macronutrients for growth and metabolism in broiler chickens. World's Poult. Sci. Ass. J., 63, 541-556.

Taouis M., Chen J.W., Daviaud C., Dupont J., Derouet M., Simon J., 1998. Cloning of the chicken leptin gene. Gene, 208, 239-242.

Taouis M., Dridi S., Cassy S., Benomar Y. Raver N., Rideau N., Picard M., Williams J., Gertler A., 2001. Chicken leptin: properties and actions. Dom. Anim. Endocrinol., 21, 319-327.

Turro-Vincent I., 1994. Ontogenèse du comportement alimentaire du poussin (Gallus 
domesticus) dans les conditions de l'élevage intensif. Thèse, Université François Rabelais, Tours, France, 205p

Turro I., Porter R.H., Picard M., 1994. Olfactory cues mediate food selection by young chicks. Physiol. Behav., 55, 761-767.

Wauters A.M., Guibert G., Bourdillon A., Richard M.A., Melcion J.P., Picard M., 1997. Choix de particules alimentaires chez le poussin : effet de la taille et de la composition. $2^{\text {èmes Journ. }}$ Rech. Avicole, Tours, France, 201-204.

Weeks C.A., Brooks C., Coe G., Danbury T.C., 1997. Effect of feed colour on food consumption of young layers and broilers. Brit. Poult. Sci., 38 (Suppl.1), S17.

Weeks C.A., Danbury T.D., Davies H.C., Hunt P., Kestin S.C., 2000. The behaviour of broiler chickens and its modification by lameness. Appl. Anim. Behav. Sci., 67, 111-125.
White B.D., Porter M.H., Martin R.J., 2000 Effects of age on the feeding response to moderately low dietary protein in rats. Physiol. Behav., 68, 673-681.

Woods S.C., Seely R.J., Porte D.J., Schwartz M.W., 1998. Signals that regulate food intake and energy homeostasis. Science, 280, 1378-1383.

Wren A.M., Small C.J., Ward H.L., Murphy K.G., Dakin C.L., Taheri S., Kennedy A.R., Roberts G.H., Morgan D.G., Ghatei M.A., Bloom S.R., 2000. The novel hypothalamic peptide ghrelin stimulates food intake and growth hormone secretion. Endocrinology, 141, 4325-4328.

Yahav S., 2009. Alleviating heat stress in domestic fowl: different strategies. World's Poult. Sci. J., 65, 719-732.

Yalçin S., Settar P., Ozkan S., Cahaner A., 1997a. Comparative evaluation of three com- mercial broiler stocks in hot versus temperate climates. Poult. Sci., 76, 921-929.

Yalçin S., Testik A., Ozkan S., Settar P., Celen F., Cahaner A., 1997b. Performance of naked neck and normal broilers in hot, warm, and temperate climates. Poult. Sci., 76, 930937.

Yo T., 1996. Adaptation comportementale au choix alimentaire du poulet de chair et de la poule pondeuse (Gallus domesticus) en milieu tropical. Thèse, Sciences Biologiques et Agronomiques. Rennes, Ecole Nationale Supérieure d'Agronomie de Rennes, France, 265 p.

Yo T., Vilariño M., Faure J.M., Picard M., 1997. Feed pecking in young chickens: new techniques of evaluation. Physiol. Behav., 61, 803-810.

\section{Résumé}

Les programmes nutritionnels reposent le plus souvent sur la base de pas de temps d'une journée minimum alors que des phénomènes associés à l'ingestion des aliments induisent des réponses selon des pas de temps beaucoup plus courts. L'ingestion est régulée à long terme au niveau central depuis des boucles de rétroaction des tissus périphériques, afin d'assurer l'équilibre énergétique, et ceci de concert avec la recherche de l'homéostasie protéique et de l'homéothermie. La régulation de l'ingestion à court terme est liée à la nécessité de limiter l'encombrement de l'aliment ingéré, et d'assurer des apports énergétiques et de nutriments réguliers. Chez les volailles, elle est vraisemblablement effective selon un pas de temps inférieur à une heure. Elle fait intervenir des signaux provenant du tractus gastro-intestinal et agissant au niveau central. Les signaux sensoriels conditionnent la réponse à très court terme $(<$ minute). Parmi eux, les capacités visuelles et tactiles sont particulièrement utilisées par les volailles pour apprécier leur aliment. Le comportement alimentaire dépend de ces différentes perceptions qui interagissent entre elles et dépendent aussi de l'expérience de l'animal. Les volailles sont capables de différents types d'apprentissage, par association de sensorialités entre elles ou avec les effets post-ingestifs de l'aliment. Ces informations sont stockées dans la mémoire à long terme et sont réutilisées par l'animal, qui est alors capable d'anticiper les effets d'un aliment qu'il apprend à identifier. Ces apprentissages, permettant à l'animal une meilleure adaptation à son environnement en améliorant sa capacité de choix, interfèrent alors avec les mécanismes de régulation de la prise alimentaire. La prise en compte des préférences alimentaires et des capacités d'apprentissage des volailles, constitue un challenge ambitieux pour les nutritionnistes.

\section{Abstract}

\section{Feed intake in chickens: do not forget short-term regulation}

Nutritional programs are usually based on a daily schedule, whereas different phenomena related to feed intake come into play on shorter timescales. Feed intake is regulated in the long-term at the central level through feedback from peripheral tissues, enabling energy balance, and also protein homeostasis and homoeothermia. The short-term regulation of feed intake is linked to the necessity to limit the quantity of feed and to provide regular supplies of energy and nutrients. In poultry, it is probably effective in less than one hour and involves signals from the gastro-intestinal tract acting on the central nervous system. Sensorial cues induce very rapid responses $(<\mathrm{min})$. These include visual and tactile abilities, which are particularly important in poultry to appreciate feed. Feeding behaviour depends on the interaction of these different perceptions and also on the animal's experience. Poultry can learn in different ways, by associating different physical cues and/or post-intake feed effects. This information is stored in the long-term memory and reused by animals, enabling them to anticipate feed effects which they have learned to identify. This learning allows poultry to better adapt to their environment by improving their ability to choose, thus influencing feed intake regulation. Taking account of poultry feeding preferences and learning abilities is an ambitious challenge for nutritionists.

BOUVAREL I., TESSERAUD S., LETERRIER C., 2010. L'ingestion chez le poulet de chair : n'oublions pas les régulations à court terme. Inra Prod. Anim., 23, 391-404. 
